\title{
Farrapos de Ideias: \\ Maria da Ilha
}

pg 55-60

Raquel Terezinha Rodrigues ${ }^{1}$

Carla Alexandra Ferreira ${ }^{2}$

Fazia tempo que pusera reparo num bando de cunhatãs passeando todos os dias na praça da República. Perguntou e soube que aquilo eram normalistas. Dormiu sonhando com elas.

(Macunaima, Mario de Andrade)

\section{Resumo}

Este trabalho se propõe a fazer uma leitura do livro Farrapos de Idéias (1937) de Antonieta de Barros, cujo pseudônimo é Maria da Ilha, com o objetivo de mostrar que a obra vai além da escrita da crônica diária e breve, como propõe a autora. Pretende-se mostrar que os assuntos tratados são os do cotidiano, que o livro é um texto híbrido em que escrita intimista e jornalística se misturam, fazendo com que a narradora/ cronista rompa com a imparcialidade proposta pelo jornalismo. E nesse misto de memória pessoal e coletiva em que a autora narra eventos ocorridos em um período, os silêncios e lacunas são reveladores de assuntos com os quais não consegue lidar. Como referencial teórico foi utilizado Philippe Lejeune (1973) e Fredric Jameson (1992).

Palavras-chave: Maria da Ilha, Farrapos de Idéias, Antonieta de Barros.

\section{FARRAPOS DE IDÉIAS BY MARIA DA ILHA}

\begin{abstract}
This essay aims at reading the book Farrapos de Idéias by Antonieta de Barros - whose nickname is Maria da Ilha (Maria from the Island) - with the objective of showing it goes beyond the brief writing of a chronicle as the author proposes. We aim to show its subjects are those of the quotidian, the text is hybrid where intimate and journalistic writings merge making the writer/chronicler break with journalism impartiality. It is in this mixture of individual and collective memory the author narrates events that occurred in a period; silence and gaps reveal issues with which she could not deal with. As theoretical support we used Philippe Leujene (1973) and Fredric Jameson (1992).
\end{abstract}

Keywords: Maria da Ilha, Farrapos de Idéias, Antonieta de Barros.

1 Mestrado em Literatura pela Universidade Federal de Santa Catarina (UFSC) e Doutorado em Literatura (Teoria Literária e Literatura Comparada) pela Universidade de São Paulo (USP). Atualmente exerce o cargo de professor adjunto da Universidade Estadual do Centro-Oeste (PR) e atua como Professora colaboradora do PPGLit/UFSCar.

2 Mestrado e doutorado em Estudos Linguísticos e Literários em Inglês pela Universidade de São Paulo- USP. Atua como Professor Adjunto na UFSCar - Universidade Federal de São Carlos, na área de Língua Inglesa e suas Literaturas, no curso de Letras e docente permanente do Programa de Pós-graduação em Estudos de Literatura - PPGLit - UFSCar. 


\section{Introdução}

Este trabalho é uma proposta de leitura da obra Farrapos de Idéias (1937) de Maria da Ilha, pseudônimo literário de Antonieta de Barros. O livro é uma compilação de crônicas "ligeiras", nos dizeres da autora, que foram publicadas no Jornal República.

Antonieta de Barros nasceu em Florianópolis (Nossa Senhora do Desterro, para os mais tradicionais) a 11 de julho de 1901, de origem humilde, filha de uma escrava liberta, que era lavadeira, órfã de pai, recebeu educação de uma professora que conhecia sua mãe, para mais tarde ingressar na Escola Normal onde concluiu o curso de Magistério. Com o ideal de lecionar, abriu seu próprio caminho ao fundar um curso primário que recebeu seu nome e do qual foi diretora até a sua morte. A irmã, Leonor de Barros, deu continuidade ao seu trabalho e o curso encerrou suas atividades em 1964, após 42 anos de funcionamento e doze anos após o falecimento de sua idealizadora.

Antonieta de Barros, além de educadora, função que desempenhou até o fim, colaborou em diversos jornais, foi Professora de Português e Psicologia do Colégio Coração de Jesus de Florianópolis, dirigido pelas irmãs da Divina Providência, um colégio que tinha como meta a educação da elite feminina da Ilha. Foi ainda nomeada Diretora do Instituto de Educação e Colégio Dias Velho até a sua aposentadoria. Na política, participou da Constituinte de 1935, sendo a primeira mulher, em Santa Catarina a ser eleita como Deputada para o Congresso Legislativo e a primeira mulher negra a ocupar esse posto no Brasil. Faleceu no dia 28 de março de 1952, como uma das figuras mais consagradas e respeitadas do estado.

O livro Farrapos de Idéias (1937) surgiu de um "instante de grande fraternidade" (ILHA, 1937, p.I). Segundo a autora, na explicação que dá, no prefácio da primeira edição, intitulado "A razão de ser deste Livro" diz ser "simples, muito simples a razão de ser de sua existência" e que o fez por sugestão da Sra Carmem Linhares Colônia, para ajudar as crianças filhas de leprosos, ou seja, do Preventório, localizado na Colônia Santana, houve facilitações, o Governo do Estado deu a impressão e Malinverne Filho emprestou seu lápis para a ilustração da capa. E salienta que se não fosse essa uma razão muito forte, o livro não existiria, pois os "seus Farrapos" deveriam ter uma vida breve como o jornal.

E ao reivindicar essa brevidade para os seus escritos, Maria da Ilha os aproxima do que Jorge de Sá (SA, 1987) diz sobre a crônica, caracterizando-a como sendo, inicialmente, um gênero jornalístico. Para ele, o fato de ser aparentemente simples, não significa que desconheça as artimanhas artísticas. Ao situar seu surgimento nos jornais, diz ter, as crônicas, herdado deles a precariedade e efemeridade do jornal, pois seu nascimento começa com a leitura e sua morte fica condicionada ao instante em que o leitor se desfaz do jornal. Com João do Rio, todavia, a crônica ganha novos ares, tornando-se mais literária, ela se afasta cada vez mais do registro formal se aproximando mais do comentário, com forte carga interpretativa, ou seja, de uma releitura do real.

Quando Maria da Ilha desloca suas crônicas do jornal, rumo ao livro, pouca referência faz às datas de publicação dos textos, algumas, no entanto, fazem menção a elementos do cotidiano, facilmente reconhecíveis, são textos que falam sobre a guerra, o natal, o ano novo, a malhação de Judas, a páscoa, o dia dos professores e o dia do trabalho. As demais crônicas falam da vida em geral, do amor de Cristo, marcando sua posição religiosa de católica e de profunda conhecedora dos textos sagrados, da defesa do ensino e da cultura e, sobretudo, da missão de ser professora, tema que inicia e encerra o livro.

Sendo assim, a escritora não se afasta totalmente do que Davi Arrigucci (ARRIGUCCI, 
1987) chama de registro da história implicando a noção de tempo, ao se ligar à etimologia do termo chronos, nem deixa de registrar ou silenciar seus anseios enquanto mulher, negra, política, educadora, em uma narrativa de si que paradoxalmente torna atemporal.

Dessa forma, o objetivo desse estudo é mostrar que Farrapos de Idéias (1937) vai além da escrita da crônica diária e breve, como propõe a autora, em que os assuntos tratados são os do cotidiano, que o livro é um texto híbrido em que escrita intimista e jornalística se misturam, fazendo com que a narradora/cronista rompa com a imparcialidade proposta pelo jornalismo. E nesse misto de memória pessoal e coletiva em que a autora narra eventos ocorridos em um período, os silêncios e lacunas são reveladores de assuntos com os quais não consegue lidar.

\section{Maria Luiza Ritzel Remédios (REMÉDIOS,} 1997), sobre a literatura confessional, diz ser essa a que se centra no sujeito, pois ele é o objeto de seu discurso. Ela a denomina de confessional ou intimista e os textos que a constituem se agrupam formando gêneros, segundo suas semelhanças, mas que o entrecruzamento entre eles é muito comum.

Lejeune (1973) ao teorizar sobre as escritas autobiográficas, estabelece pactos em que a identidade autor-narrador-personagem corresponderia. Contudo, tal perspectiva não se aplica à Maria da Ilha pelo uso de pseudônimo, quebrando assim essa identidade. Todavia, Lejeune propõe que a essa não identidade de nomes, seja estabelecido o pacto zero, que pode ser revelada pelo paratexto, como no livro em questão, uma vez que não há personagens em Farrapos de Idéias.

Renata A. P. Dranka (s/d), em um estudo consistente sobre as crônicas de Antonieta de Barros publicadas nos principais jornais de Florianópolis, diz ser a autora corajosa ao romper com seus escritos a lógica da narratividade jornalística e construir um lugar novo para o seu dizer. Para Dranka:
Foi possível perceber as estratégias dos jornais na tentativa de desmobilizar os avanços das mulheres em relação ao voto, no emprego, nas fábricas, nas escolas, discursos que as excluíam da esfera pública, adiando sua participação na construção da cidadania, discursos que evidenciavam a "faculdade maternal" e não a política, com virtudes específicas, circunscrita ao espaço doméstico, ficando cada vez mais difícil para elas superarem este limite, e quando o faziam, eram vistas como um fenômeno extravagante, não autorizado pela natureza. $\mathrm{O}$ discurso jornalístico engendra as experiências sociais conforme uma ótica pré determinada. Incluem-se a imagens das pessoas pobres, os excluídos em uma formação discursiva e a imagem dos não excluídos em outra formação discursiva. $\mathrm{O}$ encaixe, a escolha de narrar o acontecido com este ou aquele imaginário, já marca a posição do sujeito, rompendo assim com as noções de objetividade e imparcialidade. (DRANKA, s/d, p. 1-2)

Sem levantar bandeira de um discurso feminista ou socialista, esse "lugar novo" e essa "coragem", propostos por Dranka, surgem quando Maria da Ilha se coloca contra os discursos vigentes nos jornais e na contra mão dos acontecimentos, se posiciona contra a guerra sendo favorável à recusa das mulheres no serviço militar, a polêmica se dá pelo fato de estar negando às mulheres a entrada em um campo em que os homens reinam e reinarão por muitos anos, logo após elas terem conquistado o direito ao voto, mas logo se justifica dizendo que “as mulheres não devem emprestar seu esforço para o mais ingrato dos frutos do egoísmo". As guerras, segundo a escritora, não se fazem pelo bem da coletividade, e sim, para "proveito de alguns e ruína das massas".

E segue na defesa das mulheres, dizendo que o que elas necessitam é educação, relembra notícias do Rio em que "o sexo fraco", se sobressaiu pela inteligência:

Tudo isso nos fez lembrar as notícias, vindas do Rio, em que o sexo fraco, representado pelas dras. Natércia Silveira e Maria Xavier da Silveira, se pôs em defesa do sexo forte, num júri, conseguindo a absolvição do réu, criminoso de morte. Não foi sem emoção e, talvez, espanto, que se assistiu a este espetáculo surpreendente, soberbo manifesto da inteligência feminina. Depois da eloqüência dos fatos, que mais resta dizer? Inegavelmente, le monde marche... (BARROS, 1937, p. 189-190) 
E destaca que, no mundo das artes, Santa Catarina conta com três nomes femininos que "lhe servem de orgulho", são eles: a escultora Sra Florisbela Araujo Figueiredo Monteiro (D. Belinha) de "profundos dotes artísticos", a cantora Sra Ondina Gheur, que intitula de "verdadeiro rouxinol" e a pianista Srta Newtonina Costa, detentora de "uma inteligência peregrina", confirmando o que a autora diz: "depois da eloqüência dos fatos, que mais resta dizer? Inegavelmente, le mon] de marche..."

$\mathrm{Na}$ sequência dos assuntos tratados, pelas crônicas, observa-se que há uma recorrência no que diz respeito à finalidade da vida, ou seja, a ascensão espiritual. Reforça a necessidade de oferecer às massas o "pão do espírito" (BARROS, 1937, p. 22). Faz uma verdadeira ode à disciplina, à moral e à retidão do coração como "princípios da moral máxima".

\footnotetext{
"Respeita-te a ti mesmo! Edifica sôbre esta base, traça os caminhos que a lâmpada maravilhosa da consciência ilumina, para que surja, consequentemente, a estabilidade da moral social! Aplica, segundo o sábio dos Provérbios, à disciplina o teu coração, e os teus ouvidos às palavras do conhecimento. (BARROS, 1937, p.65)
}

E na crônica Primeiro de Maio, diz que o único caminho para as grandes conquistas é o trabalho e que fora dele não há como se realizar, porém lamenta que aliado a essa ânsia de vencer e de se realizar não ande o livro, e completa: "nós não precisamos de pão e circo, mas de pão e cultura". Encerra o texto abençoando os heróis anônimos que sabem cumprir o seu dever:

\footnotetext{
"Dentro do sonho lindo de pão para tôdas as bôcas, numa expectativa duma humanidade melhor, prêsa por uma fraternidade real, nós abençoamos todos os heróis anônimos das terríveis batalhas incruentas, que souberam e sabem engalanar a vida, dando-lhe brilho, fartura e alegria, com o cumprimento de dever máximo: No suor do teu rosto, comerás o teu pão, até que tornes a terra. (BARROS, 1937, p. 82-3)
}

Embora, no livro sobressaia esse tom de ânimo e de observância às virtudes, para que se tenha sucesso na vida, é inegável que na contramão do discurso, haja, também, esse descrédito na humanidade. Essa desilusão se estabelece a princípio com a guerra, em que o egoísmo humano atinge seu ponto máximo, destruindo o sonho de fraternidade que muitos teimam ter, incluindo aqui a própria autora.

\begin{abstract}
Dentro do sonho lindo de fraternidade que se envolve os corações idealistas, esbatendo fronteiras e desconhecendo oceanos, para o abraço universal, há, de quando em vez, hiatos tremendos, em que os homens se revelam.Só então é que as massas sentem e compreendem o valor e a fecundidade da paz, que é progresso, sossêgo espiritual; da paz, que é evolução e conquista; da paz que é trabalho e fartura; da paz que é glória e bênção. (BARROS, 1937, p. 31.
\end{abstract}

Para em seguida refletir sobre o natal e chegar à conclusão de que mesmo que os homens não aceitem a Cristo, que o neguem, ainda que se destruam mutuamente e "acelerem os meios de se matarem, ainda que tenham dado em troca das palavras doces oferecidas por Cristo, o escárnio, ainda assim, as palavras do mestre "tem conseguido conter os ímpetos de ferocidade". E numa hipótese que julga absurda diz que a doutrina cristã mesmo que fosse utopia, e que seu evangelho fosse apenas um sonho, ainda assim "seria Bendito".

Desvinculando-se então da idéia de que o texto significa apenas o que diz, a linguagem, de acordo com Jameson ao citar Talleyrand, foi-nos dada com o intuito de esconder nossos pensamentos. (JAMENSON,1992, p. 55-6) observa-se aqui que a autora em sua moral católica, ainda que se sinta desiludida com a vida e admita ser teimosa ao ter certos sonhos, tenta dar às crônicas esse ar de ânimo, muito embora ela mesma se mostre cansada de tanta luta.

Mas quem é Maria da Ilha? Como se autodefine? Na crônica que dá como título o seu nome ela diz que na rua onde mora, as vozes 
alegres dos garotos fazem lembrar que é véspera de São João, o mesmo santo das fogueiras e dos balões. Para ela, o destino dos balões que é subir para depois cair "é o anseio de fuga, de libertação, para cumprimento do seu inglório destino". Nessa crônica, o tom intimista percorre todo o texto, nele a autora se mostra insegura diante do futuro, de estrela singular como o balão.

O silêncio em torno de suas experiências sociais, das dificuldades e barreiras transpostas para chegar onde chegou também é uma forma de protesto e de luta, assim como os balões Maria da ilha sabe que ainda que eles dividam os céus com as estrelas, ainda assim o céu é delas, não dos balões. E mantendo o tom de ânimo mostra aos outros, seus irmãos de desventuras, que é possível vencer, que "é preciso avançar, alcançar a montanha, galgála". E nada melhor do que o exemplo da sua vida:

\begin{abstract}
A Escola, na sua função única, prepara as criaturas para a vida, - luta intensa e complexa. Os títulos podem envaidecer os nulos, os fátuos, mas não lhes permitem vencer. Só vencem os capazes. E a capacidade revela-se na ação. Só a instrução, só o livro, elevando o homem lhe dá o direito de ser homem; só a instrução consciente rouba as criaturas ao servilismo aviltante e procura alçá-las às cumiadas, onde o ar é puro e donde se descortinam todos os panoramas maravilhosos. (BARROS, 1937, p. 162)
\end{abstract}

E encerrando o livro, seguem dois discursos o primeiro feito por ocasião da formatura da primeira turma de Magistrandos do Colégio Estadual Dias Velho e o segundo intitulado Falando as Mestras é a oração de paraninfa proferida a 26 de novembro de 1945, na solenidade de formatura do Colégio Coração de Jesus de Florianópolis.

\footnotetext{
Não deixeis que a raça, a côr, a fortuna e todos êstes ridículos nadas em que se perdem, muitas vêzes, as criaturas, sejam traços de distinção, entre os pequeninos que o Senhor vos confiar. Amai-os com carinho maternal inato em tôdas nós, mas multiplicai os vossos cuidados pelos que mais pobres em fôrças morais forem. (BARROS, 1937, p. 231)
}

Aqui abandonando o pseudônimo, assina como Antonieta de Barros e se dirige às normalistas como "filhas". Antonieta as lembra que são mães e educadoras, e que o Brasil de amanhã está nelas. Essa idéia vem corroborar com opinião que tem sobre os jovens, para ela nas mãos destes está sempre o futuro, e a arma que eles podem usar para que o futuro seja vitorioso ou não é a instrução. Reforça que devem viver para os pequeninos o amor que Cristo deixou na terra.

\section{Considerações finais}

$$
\begin{array}{r}
\text { Meus senhores. Eu pararei, aqui. Ficarei aqui, } \\
\text { neste meu pensar em voz alta. Ficarei, aqui, } \\
\text { meus colegas, porque o Instituto, que vos acaba de } \\
\text { sagrar Mestres, confia em vós.Ficarei aqui, meus } \\
\text { queridos, abençoando o vosso caminho e sentindo, } \\
\text { com o coração, a certeza de que, longe ou perto, } \\
\text { onde o dever vos impuser o trabalho, nêle poreis } \\
\text { a vossa alma de barrigas verdes, para o bem da } \\
\text { Pátria comum. } \\
\text { Maria da Ilha 1937, p. 210) }
\end{array}
$$

O objetivo desse estudo foi mostrar que Farrapos de Idéias é um livro e um texto híbrido que pode ser lido pelo viés da escrita intimista, sem se afastar totalmente da jornalística, contudo tal mistura permite que a narradora/cronista rompa com a imparcialidade proposta pelo jornalismo. E nesse misto de memória pessoal e coletiva em que a autora narra eventos ocorridos em um período, os silêncios e lacunas são muito mais reveladores do que o conteúdo manifesto no texto.

Observou-se aqui que embora Maria da Ilha tente manter o bom ânimo, instigando os desanimados que estão à margem, ela mesma em alguns momentos se sente insegura diante do mundo. Demonstra em relação aos homens uma desilusão constante, pelas ações atrozes praticadas, principalmente no que tange à guerra e nas várias invenções criadas para que se matem uns aos outros, duvidando até mesmo se com tantos avanços tecnológicos houve realmente progresso. 
A saída oferecida, segundo Antonieta de Barros, está nas mãos dos jovens, a eles cabe o futuro, eles, com sua mocidade trazem um passo de avanço para a civilização. E nessa luta que se trava, segundo a autora, não se trazem somente sonhos, é preciso armas. A saída oferecida por Maria da Ilha/ Antonieta de Barros é a arma da instrução, só ela dá ao indivíduo a liberdade e venceríamos a brevidade da vida, pois segundo a autora: "chegaríamos a viver mais, porque nos preparavam a mente para pensar. E só vive, no sentido humano da palavra, o que pensa. Os outros se movem, tão somente". (BARROS, 1937, p. 160)

\section{Referências}

ARRIGUCCI JR, Davi. Enigma e comentários: ensaios sobre literatura e experiência. São Paulo: Cia das Letras, 1987.

BARROS, Antonieta. Farrapos de idéas. Florianópolis: N/D.

DRANKA, Renata A. P. Trajetórias que se cruzam. História, gênero e trajetórias biográficas. ST 42, UNISUL.

JAMESON, Fredric. O inconsciente Político. São Paulo: Editora Ática, 1992.

LEJEUNE, Philippe. "Le Pacte autobiographique". In: Poétique. Paris, 1973, p 137-162.

Je est un autre, l'autobiographie de

la littérature aux médias. Paris: Seuil, 1990

REMÉDIOS, Maria Luiza Ritzel. Literatura Confessional. Porto Alegre Mercado Aberto, 1997.

SÁ, Jorge de. A crônica. São Paulo: Ática, 1997.

Recebido em: 25 de agosto de 2017.

Aprovado em: 15 de outubro de 2017. 